\title{
CORRELAÇÃO ENTRE COMPOSIÇÃO DAS FÔLHAS E PRODUÇÃO, E TAMANHO DE FRUTOS, EM LARANJEIRA BAIANINHA $\left({ }^{1}\right)$
}

J. Romano Gallo, RÚter HiRoce, engenheiros-agrônomos, Laboratório de Análise Foliar, e ODY RoDRIGUEz, engenheiro-agrônomo, Seção de Citricultura, Instituto Agronômico

\section{SINOPSE}

Dados de produção de 4 anos de colheita (1961-64) foram estudados em relação aos elementos minerais contidos nas fôlhas com 6 meses de idade, colhidas anualmente num ensaio fatorial NPK $3 \times 3 \times 3$ de longa duração, com laranjeira baianinha (Citrus sinensis Osb.) enxertada sôbre cavalo de laranja caipira (C. sinensis Osb.). As análises da variância dos teores de $N$ e $K$ das fôlhas mostraram efeitos lineares, positivos e altamente significativos da adubação com os respectivos elementos. Esse efeito, para P, ficou limitado a uma dose do fertilizante. A adubação com superfosfato provocou, ainda, aumento no teor de $\mathrm{Ca}$ das fôlhas, significativo ao nível de $1 \%$.

Os estudos efetuados revelaram que: o aumento do teor de nitrogênio nas fôlhas aumentou a produção (pêso e número) e diminuiu o tamanho (pêso médio) dos frutos; o aumento do teor de potássio aumentou o tamanho dos frutos; e o aumento do teor de cálcio aumentou a produção (pêso). O teor de fósforo não influiu significativamente na produção ou tamanho de frutos.

\section{I - INTRODUÇÃO}

A determinação, nas fôlhas, dos elementos minerais incluídos na diferenciação dos tratamentos com fertilizantes foi efetuada no período de 1961 a 1964, em um ensaio de longa duração com laranjeira baianinha, em sequência a um primeiro estudo sôbre análise foliar dos citros, iniciado em 1957, no mesmo experimento (1). Pelos dados de análise e os de produção e pêso médio de frutos, foram obtidas certas correlações entre os teores de N, K e Ca e a produção, número e tamanho dos frutos (pêso médio). Êste trabalho trata

(1) Trabalho apresentado ao II Congresso Latino-Americano e $\mathrm{X}$ Congresso Brasileiro de Ciência do Solo, realizados em Piracicaba, Estado de São Paulo, de 19 a 30 de julho de 1965. Feito com auxilio prestado pela Fundacão Rockefeller, E.U.A., e Fundação de Amparo à Pesquisa do Estado de são Paulo. Recebido para publicação em 14 de setembro de 1965. 
dessas correlações. São aqui relatados, também, os efeitos principais da adubação e suas interações na composição das fôlhas, produtividade e tamanho dos frutos, obtidos naquele período.

\section{2 - REVISÃO DA LITERATURA}

Os trabalhos publicados em relação à influência que a adubação exerce na produtividade e qualidade dos frutos, em plantas cítricas, são numerosos, tendo Kümpfer apresentado uma revisão da literatura mais recente (6). Em nosso meio, Moreira, Fraga e Roessing (3) relataram os efeitos da adubação química e do estêrco na produção da laranjeira, no período de 1955-1962, do experimento que serviu de base ao presente estudo.

A respeito da correlação entre a análise foliar e aquelas características, os trabalhos encontrados na literatura estrangeira são em menor número e tratam principalmente da correlação entre teor de potássio e tamanho de frutos. Jones e Cree (2), referindo-se a um trabalho anterior (4), no qual se obteve correlação positiva entre a concentração de potássio nas fôlhas e tamanho de frutos, procederam a um estudo de levantamento dessa relação em pomares de laranjeira Valência, da Califórnia. Os autores concluíram que a relação varia, numèricamente, de uma para outra área, em vista do que um nível crítico de $\mathrm{K}$ nas fôlhas não pode ser generalizado para determinar a necessidade de adubação potássica, capaz de aumentar 0 tamanho do fruto. Atribuem isso a outros fatôres que, além do potássio, podem influenciar o teor de potássio das fôlhas e o tamanho dos frutos. $\mathrm{Na}$ literatura nacional, até agora nada foi relatado sôbre $o$ assunto.

\section{3 - MATERIAIS E MÉTODOS}

O ensaio é formado de laranjeiras baianinha enxertadas sôbre cavalos de laranjeiras caipira (Citrus sinensis Osbeck), plantadas em 1947, em terra roxa da Estação Experimental de Limeira. A diversificação de tratamentos, na parte relativa a fertilizantes químicos, constitui um ensaio fatorial NPK $3^{3}$, com os níveis 0,1 , e 2 , e teve início em 1951. A dose básica empregada por planta desde 1957 é a seguinte: $250 \mathrm{~g}$ de $\mathrm{N}, 200 \mathrm{~g}$ de $\mathrm{P}_{2} \mathrm{O}_{5}$ e $150 \mathrm{~g}$ de $\mathrm{K}_{2} \mathrm{O}$, sob as formas de nitrato de sódio, superfosfatado simples e cloreto de potássio, respectivamente. Outros detalhes referentes ao solo e plano do experimento são apresentados em outros trabalhos $(\mathbf{1}, \mathbf{3})$.

Dados de produção, tamanho de frutos e de análise foliar foram obtidos em 4 anos (1961-64), para cada tratamento. 
Em cada colheita, a produção foi anotada em pêso e número de frutos, e os resultados apresentados dizem respeito a quatro árvores, em cada parcela (2). A estimativa do tamanho é dada pelo pêso médio de um fruto, em gramas, calculado a partir dos dados de colheita.

As amostras de fôlhas para análise foram colhidas em fevereiro ou março de cada ano, dos ramos com frutos produzidos de julho a agôsto do ano anterior. O preparo do material e as análises de $\mathrm{N}$, $\mathrm{P}, \mathrm{K}$, Ca e $\mathrm{Mg}$ foram efetuados segundo métodos usuais do Laboratório de Análise Foliar (1).

\section{4 - RESULTADOS GERAIS}

\section{1 - EFEITOS DA ADUBAÇÃO NA COMPOSIÇÃO DAS FOLLHAS E NA PRODUÇÃO}

Os dados do quadro 1 mostram a influência da adubação nos teores de $\mathrm{N}, \mathrm{P}, \mathrm{K}, \mathrm{Ca}$ e $\mathrm{Mg}$ das fôlhas, na produção e tamanho de frutos. Todos os efeitos foram determinados, considerando-se os resultados médios de quatro anos. A variação das médias através dos anos e em função da adubação pode ser apreciada pelos gráficos das figuras 1 e 2 . Na figura 2, também é apresentada a distribuição da precipitação média mensal, no periodo de janeiro de 1961 a março de 1964. Pode-se observar certa concordância entre a pluviometria e a produção. Em 1962 e 1963, quando não houve deficiência de chuvas, as produções foram mais elevadas.

Nitrogênio - Houve efeito linear e positivo, altamente significativo, no teor de $\mathrm{N}$ das fôlhas. A aplicação de nitrato de sódio resultou, significativamente, na diminuição do teor de potássio e no aumento do teor de magnésio das fôlhas, neste nutriente até uma dose do adubo. A produção (pêso) e número de frutos aumentaram com a adubação, sendo os efeitos significativos até uma dose do adubo, enquanto o tamanho diminuiu na mesma ordem.

Fósforo - O efeito no teor de fósforo das fôlhas foi positivo, altamente significativo, e ficou limitado a uma dose do fertilizante. A aplicação de uma dose de adubo no solo produziu diminuição significativa no teor de potássio das fôlhas e no tamanho dos frutos, e aumento no teor de magnésio das fôlhas. Houve aumento no teor de cálcio das fôlhas, de acôrdo com a dose de superfosfato aplicada, significativo ao nível de $1 \%$. A adubação fosfatada deter- 









Figura 1. - Variaçāo da porcentagem de $N, P, K$ e $C a$, sôbre materia sêca, nas follhas de laranjeira baianinha, em função dos anos e da adubação. Os símbolos $N, P$, e $K$, seguidos dos índices 0,1 e 2 , representam as doses de $N, P_{2} O_{5}$ e $K_{2} O$ das adubações com nitrato de sódio, superfosfato simples e cloreto de potássio, respectivamente.

minou aumento da produção em pêso e número de frutos, significativo ao nível de $5 \%$.

Potássio - Relações lineares altamente significativas foram obtidas entre a adubação com cloreto de potássio e cada um dos teores de potássio e de magnésio das fôlhas. O efeito foi positivo, no primeiro caso, e negativo, no segundo. Houve aumento significativo de produção e de tamanho de frutos determinado pela adubação potássica. Quanto à influência no tamanho, não houve diferença entre uma e duas doses do fertilizante, quando se consideraram os resultados médios.

Interações - Nitrogênio e fósforo, aplicados conjuntamente, provocaram aumento significativo no teor de fósforo das fôlhas, 


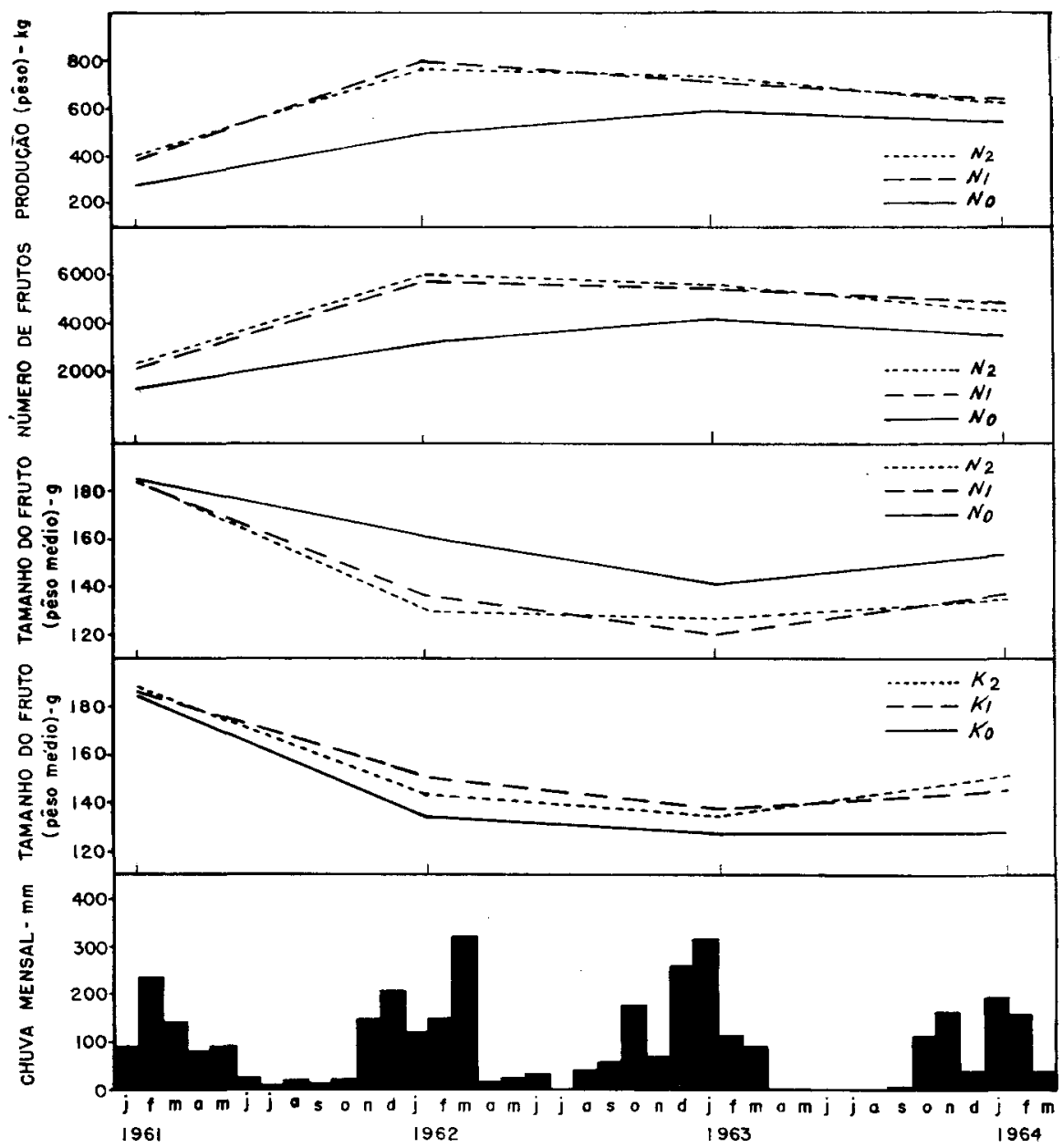

Figura 2. - Variaçāo da produção de laranja, número e pêso médio de frutos, em função dos anos e da adubação. Os símbolos com indices $N_{g}, N_{1}, N_{o}$ e $K_{z}, K_{l}$ $K_{0}$ especificam os elementos fertilizantes $N$ e $K_{2} O$ e respectivas doses. Na parte inferior da figura, aparece a precipitação média mensal, na Estação Experimental de Limeira, no período de janeiro de 1961 a março de 1964, segundo dados colhidos pela secção de Climatologia Agricola, do Instituto Agronômico.

na produção em pêso e número de frutos, e redução do tamanho. Houve interação negativa, altamente significativa, da adubação com nitrogênio e potássio no teor de magnésio das fôlhas. Não foi significativa a interação fósforo-potássio. Sòmente foram calculados os efeitos lineares das interações. 


\section{2 - RESULTADOS DOS ESTUDOS DE CORRELAÇÃO}

Desde que os elementos fornecidos nas adubações afetaram os teores de N, P, K e Ca das fôlhas e a produção, as correlações foram investigadas quanto a êsses elementos. $O$ cálcio foi carreado com a adubação de superfosfato simples, sendo portanto, fornecido também em três doses: 0,1 e 2. Assim, não se tentou relacionar o teor de magnésio com a produção, uma vez que êsse nutriente não foi incluído nos tratamentos.

Os coeficientes de correlação e regressão foram obtidos com os dados de 27 tratamentos diferentes nos quatro anos, para um tota! de 108 observações, em cada característica.

A correlação entre o teor de nitrogênio ( $N, x)$ nas fôlhas e produção (quilogramas por parcela de quatro árvores, $\hat{y}$ ) foi altamente significativa, $\mathrm{r}=0,35^{* *}, \hat{\mathrm{y}}=-1,06+247,29 \mathrm{x}$. O teor de nitrogênio também correlacionou com o número de frutos, $r=$ $=0,40^{* *}$, e tamanho, $\mathrm{r}=-0,36^{* *}$.

Houve correlação entre o teor de potássio $(K, x)$ nas fôlhas e o tamanho de frutos (pêso médio de um fruto em gramas, $\hat{y}$ ), $\mathrm{r}=0,52^{* *}, \hat{\mathrm{y}}=101,20+32,56 \mathrm{x}$.

$\mathrm{O}$ teor de cálcio $(\mathrm{Ca}, \mathrm{x})$ das fôlhas mostrou-se positivamente correlacionado com a produção (pêso, $\hat{y}$ ) $, r=0,51^{* *}, \hat{y}=108,48+$ $120,26 \mathrm{x}$. Não foi obtida nenhuma correlação entre o teor de fósforo (P) das fôlhas e produção, número ou tamanho de frutos.

\section{5 - DISCUSSÃO}

Os resultados apresentados sugerem alguns aspectos de interêsse quanto à resposta às adubações nos citros. Foram obtidas correlações entre o teor de nitrogênio das fôlhas e produção, indicando que a produção cresce em pêso e número de frutos e o tamanho diminui com o aumento do teor dêsse elemento nas fôlhas. $O$ tamanho dos frutos cresce com o aumento do teor de potássio das fôlhas. Por outro lado, a adubação nitrogenada determinou um decréscimo geral do teor de potássio das fôlhas e também no tamanho dos frutos. Em vista dêsses resultados, a diminuição do tamanho de frutos poderia ser atribuída, além do aumento do número de frutos por árvore, determinado pela adubação nitrogenada, ao efeito depressivo dêsse tratamento sôbre o teor de potássio das fôlhas.

A análise da variância revelou efeito positivo da adubação fosfatada nos teores de fósforo e cálcio das fôlhas e na produção (quadro 1). Não se obteve correlação entre o teor de fósforo nas fôlhas e produção. Obteve-se, porém, uma correlação positiva, alta- 
mente significativa, entre o teor de cálcio das fôlhas e a produção, o que parece justificar os efeitos, na produção, devidos à adubação com superfosfato simples.

Os dados obtidos evidenciam o interêsse para um contrôle da adubação com nitrogênio e potássio na laranjeira; a primeira, pela resposta obtida no aumento de frutos, e a segunda, devido ao aumento verificado no pêso médio dos frutos. Evidentemente, além do número e tamanho de frutos, devem ser considerados os efeitos sôbre outras características ou qualidade do fruto, como textura, porcentagem de suco e sólidos solúveis totais (5).

\section{6 - CONCLUSÕES}

Os resultados do trabalho permitiram estabelecer as seguintes correlações significativas:

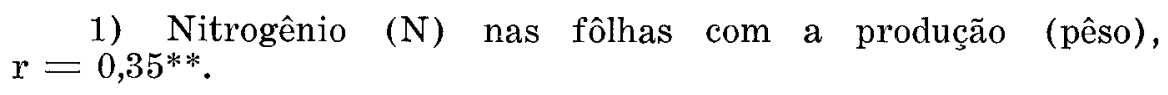

2) Nitrogênio nas fôlhas com o número de frutos, $x=0,40^{* *}$.

3) Nitrogênio nas fôlhas com o tamanho (pêso médio) de frutos, $r=-0,36^{* *}$.

4) Potássio (K) nas fôlhas com o tamanho de frutos, $r=$ $=0,52^{* *}$.

5) Cálcio (Ca) nas fôlhas com a produção (pêso), $\mathrm{r}=0,51^{* *}$.

CORRELATION BETWEEN LEAF COMPOSITION AND YIELDS, AND ORANGE FRUIT SIZES, AS AFFECTED BY FERTILIZATION

\section{SUMMARY}

Orange yields and the size of the fruits harvested in the years 1961 to 1964 were related with the content of nitrogen, phosphorus, potassium, and calcium in six-month old leaves collected each year in a long-term experimental orchard with Baianinha orange trees (Citrus sinensis, Osbeck), at the Citrus Experiment Station of Limeira, State of São Paulo. The trees were budded on sweet orange rootstock ( $C$. sinensis, Osb.) in a factorial experiment NPK $3 \times 3 \times 3$ started in 1951. The average weight or size of the fruit was calculated from the weight record and the total number of fruits from each plot or treatment.

The influence of applied fertilizers on foliage composition and tree response (production, fruit size) was also reported. Analysis of variance of the 
data obtained revealed several differences due to the fertilizer treatments to be significant, as can be seen in table 1 .

The following correlations were found to be significant:

1. Leaf nitrogen with yields (weights), $\mathrm{r}=0.35^{* *}$.

2. Leaf nitrogen with number of fruits, $r=0.40^{* *}$.

3. Leaf nitrogen with fruit sizes (average weights), $r=-0.36^{* *}$.

4. Leaf potassium with fruit sizes (average weights), $\mathrm{r}=0.52 * *$.

5. Leaf calcium with fruit yields (weights), $\mathrm{r}=0.51^{* *}$.

Leaf phosphorus was not significantly correlated with yields (weights), number of fruits, or fruit sizes.

\section{LITERATURA CITADA}

1. Gallo, J. R., Moreira, S., Rodriguez, O. \& Fraga, C. G. (Júnior). Composição inorgânica das fôlhas de laranjeira Baianinha com referência à época de amostragem e adubação quimica. Bragantia 19:[229]-246. 1960.

2. Jones, W. W. \& Cree, C. B. Leaf potassium vs. fruit size in Valencia oranges. Calif. Citrogr. 38:174-176. 1953.

3. Moretra, S., Fraga, C. G. (Júnior) \& Roessing, C. Aăubação da laranjeira: efeitos de $\mathrm{N}, \mathrm{P}, \mathrm{K}$ e estêrco sôbre a produção. Cienc. e Cult. $15: 224-225.1963$.

4. PARKer, E. R. \& Jones, W. W. Orange fruit sizes in relation to potassium fertilizations in a long-term experiment in California. Proc. Amer. Soc. Hort. Sci. $55: 101-113.1950$.

5. Reuther, W. \& SMith, P. F. Relation of nitrogen, potassium, and magnesium fertilization to some fruit qualities of Valencia orange. Proc. Amer. Soc. Hort. Sci. 59:1-12. 1952.

6. UexküLl, H. R. v. Nuevos conocimientos sobre la fertilización de citricos. Hannover, Verlagsgesellschaft für Ackerbau MBH, 1963. p.104 (2. edição, revista por M. Kümpfer). 